\title{
Towards the design and implementation of a Smart City in Bogotá, Colombia
}

\author{
Hacia el diseño e implementación de una ciudad inteligente en Bogotá, Colombia
}

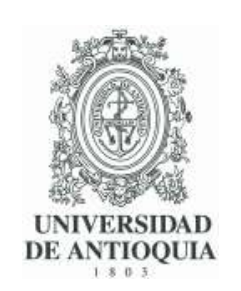

\section{Nancy E. Ochoa Guevara (D) ${ }^{1 *}$, Cesar 0. Diaz (D) ${ }^{2}$, Manuel Dávila Sguerra (D) ${ }^{3}$, Marcelo Herrera Martinez (D) ${ }^{4}$, Oscar Acosta Agudelo (iD) ${ }^{4}$, Javier A. Ríos Suarez (iD) ${ }^{1}$, Aura P. Munar Rodriguez (D) ${ }^{5}$, Gabriel A. Álzate Acuña (D) ${ }^{6}$, Andrés C. López Garcia (iD 6}

\author{
${ }^{1}$ Programa de Ingeniería de Sistemas, Facultad de Ingeniería, Corporación Universitaria Minuto de Dios. Calle 81B \# 72B-70. C. P. \\ 111011. Bogotá, Colombia. \\ 2Departamento de Ingeniería, Facultad de Ciencias Naturales e Ingeniería, Universidad de Bogotá Jorge Tadeo Lozano. Carrera 4 \#22-61. \\ C. P. 110311. Bogotá, Colombia. \\ ${ }^{3}$ Departamento de Ciencias y Tecnologías para la Vida, UNIMINUTO. Calle 90 \# 87-69. C. P. 111021. Bogotá, Colombia. \\ ${ }^{4}$ Programa de Ingeniería de Sonido, Facultad de Ingeniería, Universidad de San Buenaventura. Carrera 8H \#172-20, Colombia \# 13-32. C. \\ P. 110141. Bogotá, Colombia. \\ ${ }^{5}$ Departamento de Informática y Electrónico, Facultad de Ingeniería, Corporación Universitaria Minuto de Dios. Calle 81B \# 72B-70. C. P. \\ 111011. Bogotá, Colombia. \\ ${ }^{6}$ Programa de Electrónica, Facultad de ingeniería, Universidad Distrital Francisco José de Caldas. Carrera 7 \# 40B-53. C. P. 111321. \\ Bogotá, Colombia.
}

\section{CITE THIS ARTICLE AS:}

N. E. Ochoa and et.al.

"Towards the design and implementation of a Smart City in Bogotá", Revista Facultad de Ingeniería Universidad de Antioquia, no. 93, pp. 41-56, Oct-Dec 2019. [Online]. Available: https : //www .doi .org/ 10.17533/udea.redin. 20190407

\section{ARTICLE INFO:}

Received: October 26, 2018 Accepted: May 02, 2019 Available online: May 02 , 2019

\section{KEYWORDS:}

Community, innovation, georeferentiation, society, virtuality

Comunidad, innovación, georeferenciación, sociedad, virtualidad
ABSTRACT: With the aim of improving the citizens quality of life; the study, design and development of smart cities have been worked in different parts of the world and Colombia is not excluded. Accordingly, this document presents the advances in the implementation of a platform prototype for joining smart developments in some universities from Bogotá-Colombia. First of all, some aspects to consider in the development of a Smart City are presented. Later, the importance of virtual environments and noise studies, the drain gratings to avoid flooding by rain and the use of the bicycle as an alternative means of transport is also shown.

RESUMEN: El estudio, diseño y desarrollo de ciudades inteligentes con el objetivo de mejorar la calidad de vida de los ciudadanos se ha venido trabajando en varias partes del mundo y Colombia no es ajena a esta realidad. Es por eso por lo que en este documento se presentan los avances obtenidos en la implementación de un prototipo de plataforma para articular desarrollos inteligentes en algunas universidades de la ciudad de Bogotá-Colombia. En primera medida, se presentan aspectos a considerar en el desarrollo de una ciudad inteligente. Para terminar, también se trata la importancia de los entornos virtuales y estudios de ruido, rejillas de sumidero para evitar las inundaciones por lluvia y el uso de la bicicleta como medio alternativo de transporte aplicados bajo el concepto de ciudades inteligentes.

\section{Introduction}

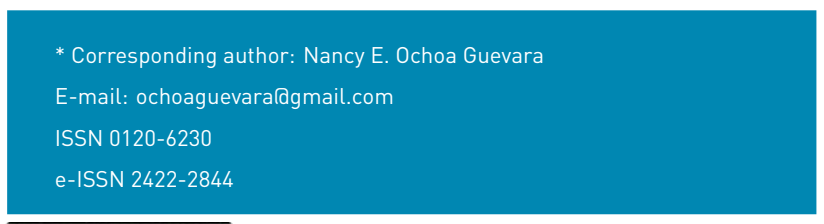

In the latest news, there are revolutionary ways with cutting-edge technologies for the development of smart cities. Currently, these ideas have arrived in Colombia with the aim of improving the quality of life of citizens and the prosperity of cities. The smart city is defined as 
the effective integration of physical, digital and human systems in the environment to offer a sustainable, prosperous and inclusive future for its citizens [1]. The proposed definition describes the basic meaning of Smart City, in which a better future is built for the next generation.

Government plans [2] encouraged a comprehensive conception of urban development in Colombia, under the concept of "Friendly and sustainable cities for equity".

In the framework of comprehensive urban actions and the strengthening of regional and local planning and management instruments, the coherent planning and the action that articulates populated places, drinking water, basic sanitation and the urban mobility, are based on the concept of "friendly and sustainable cities for equity" [3].

Besides, it is important to say that the articulation between education in Colombia and the productive sector is incorporated in the approach of Colciencias (Administrative Department of Science, Technology and Innovation in Colombia), where it is considered that research from innovation and competitiveness must be oriented towards five fundamental areas: I) identification and sustainable use of biodiversity, II) use and preservation of water resources, III) development of electronic products and materials, IV) development of research in health sciences and V) studies in Colombia with regard to peace and social cohesion. These five areas are developed in different programs from which the formation of human resources and the generation of intellectual production as a contribution to sustainable development are sought [4].

Some works related to smart and sustainable cities have been included, in a conjectural way, in some projects developed in Colombia. However, the creation of the Focus Group on Smart Cities of the Network of Universities of Bogotá called RUMBO (in Spanish: Red Metropolitana de Universidades de Bogotál became, recently, true. This group creates a "space" where universities can join to work on future projects on smart and sustainable cities. The first project to be developed between these universities is called "Digital District" and it is expected to contribute to the building of the additional services since they have already developed prototypes linked to the concept of Smart Cities.

The first known "Digital District" in Colombia was developed in Bogotá at Minuto de Dios University (UNIMINUTO) in the second semester of 2010. The project was uploaded in 3D format to Google Earth, and a group of 18 teachers and 1200 students worked using the online government manual of web 2.0. The methodology was designed and implemented with students to model a neighborhood of approximately $2.7 \mathrm{~km}$ creating a taxonomy to define the main services that would be offered to the community, Figure 1 shows some of the models made in 3D. In the project "Digital Neighborhood" of the Focus Group on Smart Cities, a methodological design is generated for the implementation of Smart city using the experiences of Uniminuto, initially within a radius of 300 meters of each university from Bogotá, and it is about validating it with some suitable tools. Within the theoretical objectives of the work, we have the exploration of the current situation of the city, specifically, Bogotá.

The empirical objective of this work is to develop the methodological design of Smart City for Bogotá and also try to identify the concrete practical solution. The empirical part of the project is also to create something which originates from the solutions designed in the practice with the help of empirical methods chosen for validation.

The structure of the document is as follows: the first section is about the introduction, the second one about the context of the smart city, the third one about the project methodology, the fourth one about the scope of the project and the last one introduces conclusions and the work that is expected to be carried out.

\section{Experimentation}

The strength of the group lies in the knowledge of the project of prototypes already made, some of them in the context of Smart Cities, some others on technologies that have relevant applications and others in the model that has been defined by the group.

First, we should start from an adequate definition of what a Smart City is, consulting other references that would strengthen a proper definition for the proposed objective.

For this reason, we must consider the process of progressive urbanization, that is, the concentration of inhabitants in the peripheries of the city and its surroundings, and its consequences (positive and negative), which currently reaches a level of specialized and secular awareness. The conceptual idea of smart cities combines efficiency, sustainability and progress in modern times and brings adequate solutions for the coming crisis, from the point of view of overpopulation and excessive consumption of resources.

There is also an explanation of the word "smart" which means the effective use of resources thanks to the modern communication and information technologies, always focusing on the well-being of people; for example, the emissions and their negative effects on the environment. 


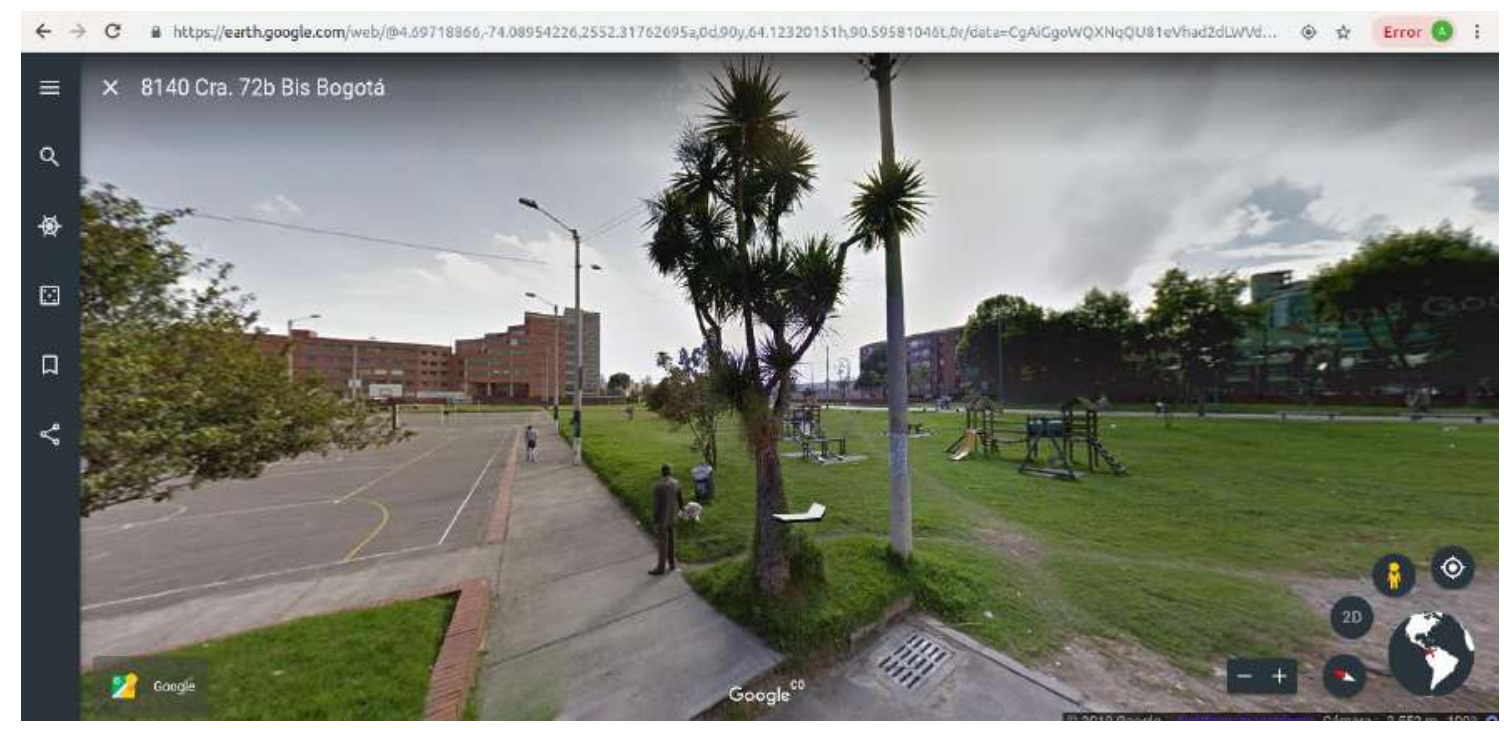

Figure 1 Google Earth 3D view of Uniminuto in Bogota, Colombia

In this sense, we understand emissions such as substances and polluting gases, but also as the residues of plastics and other materials produced by the human being, which should have low concentrations for self-protection. In this way, "intelligence" in the proposed sense should be applied, as far as possible, to all services and applications of technology for the city.

\subsection{Importance of the definition of "smart city" in Bogotá}

In [5], they emphasize that this definition depends on the context where it is used, which limits its generalization. As noted by Copenhagen Cleantech Cluster [6], a non-smart city can be defined as:

- It is overpopulated from the point of view of the surplus of automobiles, food, water, energy, etc.

- Individual components and city networks cannot communicate and work as a group.

- Individual components and city networks are static.

- The interested parties are not connected at any time with the decision and planning processes of the city [5].

In 2006, a model of vehicular traffic was designed to evaluate the traffic on a main road in Bogotá through some traffic lights which, later, could be synchronized using the Fuzzy Inference System based on Adaptive Networks to maintain the maximum allowed speed of the vehicles on the road. This model was simulated in the Matlab software and the results are evaluated at the macroscopic level with the fixed timing model that currently works in Bogotá [7].
Thanks to the flexibility of the definition of Smart City, we often find misunderstandings in the concept, confusing it with a marketing tool to achieve visibility or to publicize certain technologies. According to the multidisciplinary concept, [8] presents a thesis of the concept of self-satisfaction, where he criticizes the fact that some governments use the concept of Smart Cities in a popular way, emphasizing only the ICT part, without taking into account other important factors as the human one.

The non-unification and ambiguity of the concept is due to its interdisciplinary origin, which in the past was defined several times by different institutions, despite the fact that these definitions are descriptive rather than normative [9]. In addition, these definitions are, in most cases, affected by the objectives of their use and are delimited by the area of use (environmental, for example). [10] Warn that some of the approaches define smart cities as part of the digital revolution, which leads to a dynamic integration of modern technology in almost all areas of life, including state administrations or the cities [10].

[11] define the concept of Smart City in a broader context, such as the mixture of three basic aspects (technology, population and institutions):

- The technological dimension is divided into: digital city, Smart City, omnipresent city, network city, hybrid city and information city.

- The human dimension is divided into a creative city, a city in the process of education, a human city and a conscious city.

- The institutional dimension is divided into a smart community and a smart developing community. 
[12] defines the smart city as a place where technology is properly combined with the organizational and institutional capacity to improve the quality and sustainability of citizens' lives [12].

In addition, [13] presents the concept of smart city as a city where its economic functioning, population, administration, mobility, environment and living standards work well and is built with funds of conscious and independent citizens.

\subsection{Towards a definition of Smart City for the City of Bogotá}

With the considerations presented above and taking a starting point, we see the need to define examples of the practical life of a Smart City adding the different experiences brought by the network universities. To begin with, the experience of the digital neighborhood research project developed at the Minuto de Dios University will be used as a reference. During this process 1,200 students from five faculties of the UNIMINUTO Headquarters and from 27 different programs such as technology, engineering, administration, psychology, social work, philosophy, among others, participated in identifying the properties of the neighborhood of Minuto de Dios neighborhood.

The first element used was an official map of the neighborhood issued by the Agustín Codazzi Institute, where a design was made and a software was used to model each one of the buildings and houses from the neighborhood. This pedagogical work allowed the students to recognize their university context and to learn technological tools for social purposes.

Then, the Google Earth platform showed 1300 properties composed of houses and buildings in 3D, as well as 8 layers of information to address problems identified as a priority by residents, merchants and visitors. An example of the Uniminuto 3D building can be seen in Figure 1.

In the introduction of this experience in another Bogota neighborhood, the cartographic information of the University's environment (brought by IDECA) and the 3D model of the University's environment, will be taken as an initial reference and will be designed on a digital platform, which consists of the survey of the buildings and attributes of the space objects, covering an approximate area of up to 300 meters around.

In addition, a roles design is proposed (Coordinator, teacher and student) in which the methodology applied by UNIMINUTO in each one of the universities will be adapted and adjusted as previously stated. For example, the pedagogical praxeology Participatory Action Research (PAR), the participation of the actors (students, teachers and community of the environmentl and applied research. Likewise, the project will seek to implement the platform under the free software tools which allow technological mobility free of licensing costs and high technological quality.

In the initial discussions, layers of implementation were introduced that went from simple discussions to elements that would make up the proposed taxonomy that best represented the proposed objectives, always thinking of local needs, the characteristics of our population and the technical feasibility of the implementations.

\section{Results and discussion}

Aspects like the noise map of the areas surrounding the universities, the digitalization of relationships between people, commerce and the environment of the areas of action of each university belonging to the project, bring valuable information to make decisions about urban development and to be able to leverage it with the use of technology, the improvement of elements such as transport, home or energy efficiency, among others, trying to achieve a better management of resources and a lower impact on the environment.

From all this comes the scope that we propose and mention below.

\subsection{Scope}

The main objective of the project is to develop a system that impacts several aspects of smart cities in the member universities from Bogotá-Colombia. First of all, it is considered to cover a radius of 300 meters from each university where students, professors and researchers will capture, record and process geographic and non-geographic information. Then, this information will be taken to a database where a GIS software can read and visualize it. Here you find the main aspects of smart cities to consider.

\section{Commerce}

One of the possible immediate projects is to implement the Augmented Reality as an advertising strategy of products and services of commercial premises located in the vicinity of some universities. In coordination with the private company, a store management system is proposed to deliver to some beneficiaries of the neighborhood a tablet, a barcode reader and a ticket printer to manage their businesses with cutting-edge technology. 


\section{Health}

The use of digital and mobile technology is creating smart health solutions for people residing in urban centers. The Internet of Things (IOT) revolution that has spread in the energy, transportation, security and infrastructure segments will have radical results in health care. An only health system, the collection and exchange of data and the analysis and research practices will help, in a new era, to address current health problems.

A society is built by its people. A healthy society creates the right balance in all levels of life. Over the years, advancement in the medical sciences created an effective diagnosis and solutions for many nefarious diseases. But the increase of the population and the urban lifestyle demand a network of smart medical attention that can take care of its employees in a faster and more efficient way.

Within the Health dimension, it is proposed to have a primary health care service for the elderly, a large population in the neighborhood that requires a close and efficient service. This includes the latest digital and mobile devices that are smart in the sense that they help doctors to cure a disease or face it at the right time (diagnosis and prevention). Thus, the Internet of Things (IOT), which in health care works through sensors and collects patient data remotely, would be applied. These data can be stored and analyzed by doctors, researchers and health professionals for better diagnosis and solutions. These digital records save costs and time for patients and hospitals, since they not only offer personalized treatments and medicines, but also provide preventive measures by collecting data in real time. Given that this is the future of healthcare, many companies are investing in IOT medical devices and laptops that collect data and compile in a structured manner. This is also done using Artificial Intelligence (Al) for the evaluation and possible outcome of these data for quick solutions. Many times, when the specialized doctors are in another location, the help of the robots, which are not only machines but also software, is used to communicate, diagnose and collaborate in the treatment of patients.

To provide better health services, medical and pharmaceutical companies, health professionals, researchers and municipal administrators are working on solutions and IOT devices that can minimize response time, offer rapid emergency services, reduce overcrowding in hospitals, provide Remote treatment and collaborate with doctors around the world. Because this project is a smart city prototype around some universities, initially reduced emergency information will be processed. Soon, this prototype will be improved, for example, to admit massive emergency calls from citizens.

\section{Education}

Thinking about the inhabitants of a neighborhood, technology becomes a communication tool for people considered normal but also for those with various disabilities such as deafness, so that older adults are helped to break barriers of communication with their peers and their family where the children and grandchildren are included. In these cases, the use of e-mail to communicate and the new tools of talks through mobile to communicate with their relatives democratize access to information, in this case as the axis of communication between people. This also offers the opportunity to bring more sophisticated technologies for the sake of innovation, as the $3 \mathrm{D}$ environments inspired in Second Life cities, and to encourage maximum integration in citizen education processes using free equivalent software.

Similarly, in Bogotá in the Restrepo neighborhood, the project of inclusive mobility with the National Institute for the Blind - $\mathrm{INCl}$ and the RedVida Foundation began in 2017. The project showed that it was possible to identify the characterization of the blind and low vision population that inhabit the neighborhood as well as the frequency of their mobility in it. As the Smart Cities project is a construction of permanent developments, it is expected to design and build, through braille, a report about the warnings and the quality of the roads, as well as the distance and time needed to move from a street or avenue with the use of smart artifacts. By 2022, it is expected that these devices can be used in other neighborhoods and cities.

\section{Environment}

Cities are responsible for up to $70 \%$ of global greenhouse gas emissions and for consuming $75 \%$ of global energy [14]. These large communities offer challenges and opportunities for environmentally conscious developers. To make them more sustainable, the design and practice of the building, as well as the perception and lifestyle, must adopt a sustainability approach. These figures are often repeated but taking measures on this scale requires technological and socio-institutional innovations. Efforts to reduce urban emissions face the complexity of coordinating broad coalitions of action among governmental, private and civil society actors, and the need to collect, share and analyze new and existing data from all these isolated sectors. The effective implementation of smart cities requires an integrated and interdisciplinary approach to sustainable development. To ensure a low carbon, water and ecological footprint with an infrastructure designed to adapt to the current and future impacts of climate change, developers should consider the following aspects at the design and project 
planning stage:

- Land use planning

- Green buildings and energy conservation

- Decrease in disaster risk

- Efficiency in the reuse and recycling of water

- Solid waste management

- Sustainable transport

- Ecology and Biodiversity

- Community

A sustainable city or ecocity is a city designed taking into account the environmental impact, inhabited by people who reduce the inputs of energy, water and food, and the production of heat waste, air pollution: $\mathrm{CO}_{2}$, methane and water contamination. Richard Register used the term "ecocity" for the first time in his 1987 book, Ecocity Berkeley: building cities for a healthy future. Other important people who talked about sustainable city are the architect Paul F Downtown (who later founded the company Ecopolis Pty Ltd.) and the author Timothy Beatley, who has written a lot about this topic. The industrial ecology is sometimes used to plan these cities. A sustainable city can feed itself with minimal dependence on the surrounding countryside and can be improved with renewable energy sources. The most important aspects include to create the smallest possible ecological footprint, to produce as little pollution as possible, to use the land efficiently and to promote the use of used materials and therefore, the city's overall contribution to climate change will be minimal, if these practices are met.

These ecological cities are achieved through various means, such as:

- Different agricultural systems, such as agricultural plots within the city (suburbs or center). This reduces the distance that food has to travel from one field to another. The practical work of this can be done through small-scale / private agricultural plots or through large-scale agriculture (for example, agricultural farms).

- Renewable energy sources, such as wind turbines, solar panels or biogas created from wastewater. Cities provide economies of scale that make such energy sources viable.

- Several methods to reduce the need for air conditioning la massive demand for energyl, such as planting trees and lightening surface colors, natural ventilation systems, an increase in water characteristics and green spaces equivalent to at least $20 \%$ of the surface of the city. These measures counteract the "heat island effect" caused by the abundance of asphalt, which can cause urban areas to be several degrees warmer than the surrounding rural areas, up to six degrees centigrade at night.

- Improvement of public transport and an increase in pedestrianization to reduce car emissions. This requires a radically different approach to urban planning, with integrated business, industrial and residential areas. Roads can be designed to make driving difficult.

- Optimum construction density to make public transport feasible but avoid the creation of urban heat islands.

- Solutions to reduce urban expansion, looking for new ways to allow people to live closer to the workplace. Given that the workplace tends to be in the city, downtown or urban center, they look for a way to increase density by changing the obsolete attitudes that many inhabitants of the outskirts have toward the downtown areas. One of the new ways to achieve this is through solutions developed by the Smart Growth Movement:

- Green roofs

- Transportation of zero emissions

- Construction of zero energy

- Sustainable urban drainage systems

- Energy conservation systems / devices

- Xeriscaping: design of gardens and landscapes for water conservation

In Colombia, the most transcendental result of this effort has been the creation of a new paradigm, Sustainable Development, through which some socio-economic development needs become compatible with the conservation of the environment, to guarantee a higher quality of life to future generations [15] (Presidency of the Republic, 1996).

Joint work with owners of commercial premises to recycle more and pollute less, a strategy that allowed the use of solid waste avoiding sending them to Doña Juana Landfill, reaching a recycling figure of 109 tons where they work with an association of recyclers ANRT; working in the search for alternative energies contributes to the mitigation of the effects of climate change. The Smart Ecosystem has a meteorological network that generates data that over the years will have enough data to make weather forecasts.

In this aspect, it is clear that it is not only about applying technologies but about citizen training so that their 
behavior with the environment is regulated by prior knowledge and permanent attitude of protection towards the environment.

Another advance made in 2018 in Bogotá is the recognition of the use and accessibility of drain gratings in the boundaries of the Minuto de Dios University Corporation with the management and control of climate change. This project starts with 45 students, 12 professors and 23 people from informal commerce located on the edges of the University. Its solution has been referenced in a 3D environment with the use of augmented reality and geo referential maps, with the support of a software functional prototype architecture in geotechnics that allows using the social network Facebook and mobile devices to keep updated about the community of the neighborhood in three aspects: flooding by rainwater, contamination of the environment by bad odors and accidents due to the theft of the grids through the IT-Uniminuto research group and accompanied by the seedbed technological and innovative solutions of the engineering program of systems of the faculty of engineering. By 2022, it is expected that the university has a smart solution through the use of simulators that allow synergies to be made in similar neighborhoods.

At the terrace of University Jorge Tadeo Lozano, an urban apiary was built that houses about half a million bees. It seeks to help preserving the species and producing pollen for human consumption. The project would not only preserve a key species for human beings, but would help to guarantee food security both directly and indirectly, because thanks to the apiaries, Apisgreen (mechanism used in urban spaces) obtains honey, pollen and other products from the 18 that bees make in their hives. An alternative to the structure of the enclosure of the apiary was proposed, taking advantage of the guadua at an aesthetic level, flexibility to the wind and resistance, this being the first structure of its kind to be manufactured in Bogotá. Similarly, through the hotbed of loT and Big Data of the Engineering Department of the University, they are carrying out a project that allows, by means of heat sensors, humidity, vibration and heat, among others, to monitor bees and their production of mielilares.

\section{Transport and mobility}

Urban transport is responsible for a third of the greenhouse gas emissions that exist. Therefore, the European Commission says it is necessary to change the European transport system, as well as the behavior of society and companies with regard to mobility and start promoting an integrated and more efficient mobility system and towards the use of alternative fuels to reduce pollution and greenhouse gases. The use of natural gas as fuel is an alternative that is spreading in many countries in
Latin America and Europe, such as Italy. In Spain, this fuel which is used not only in cars, but also in heavy vehicles, is becoming increasingly popular to the point that last year it became the most used alternative fuel, where natural gas increased by more than $20 \%$, according to data from the Iberian Association of Natural Gas for Mobility (GASNAM).

This increase is justified by ecological reasons, since its emissions are considerably reduced with respect to gasoline and diesel, and also in economic terms, since it represents a saving of up to $50 \%$ and $30 \%$ in cost per kilometer compared to these fuels. Other heavier means, such as trucks, ships or trains, or even public transport in large cities, such as buses, are also increasingly betting on the use of this energy source. Its use improves the impact of transport on the environment and serves as an example of the change that is taking place in the world.

This project involves two important environmental and economic aspects, which require high technology and good behavior of people. It is compatible with the optimization of traffic flows, as well as the interactions with different groups of citizens in their habitability and availability in their mobility, as well as the quality of local transport services. Likewise, the smart coordination of electric vehicles [15] will be considered to promote this ecological transport system.

\section{Solid waste management}

The management of solid waste is another element to be improved. The report "Smart Cities: 2030: Vision document" of the $\mathrm{GICl}$ points out that the pollution waste produced by the cities must be processed, recycled and valuated energetically. One way to reuse this waste is biomethane, from biogas, a renewable gas coming, among other origins, from the decomposition of organic waste and that can be used as a fuel for transport or injected directly into the natural gas distribution network so that it can be consumed by a home, industry. The use of biomethane is already being investigated in several projects throughout the country.

The important thing of the project is that this issue should be worked directly with the population of the neighborhood or sector closer so that the appropriation of the subject and the training result in the expected.

\section{Domotics}

At the energy level, we are also experiencing a process of transition from a centralized energy system to a new model with multiple distributed energy resources, which are integrated into an increasingly decentralized system. To respond to the new energy needs of today's society, companies are developing their electricity networks in 
Spain with the aim of turning them into smart networks or smart grids and that consumers have an active role in decision-making. With smart meters, users will have on-demand energy consumption. At the same time, energy distributors are replacing their group of analog meters with smart meters. These devices differ from the traditional ones because they are more automated and provide us with valuable information about the users and their consumption.

Using this type of meter, users can have the power of decision, choice and energy management. They will know the data in real time, which can help facilitate savings (by choosing the tariff that suits the user's needs) and, with this, help the responsible use of energy. The replacement of our accountants began some years ago and, according to current legislation, we must all have these new devices before 2019. For now, according to the calculations of the National Commission of Markets and Competition (CNMC), at the close of the first semester of 2016, there were more than 28 million meters installed in Spain, $62 \%$ of the entire park, although this percentage is much higher in some distributors, which have already exceeded $90 \%$.

\section{Energy efficiency}

In this energy transformation, we find buildings or neighborhoods of almost zero consumption (NZEB, for its acronym in English, Net Zero Energy Buildingl or blocks of positive energy (PEB), which point to energy self-sufficiency and even production net of energy in buildings or districts, based on a reduction in consumption, integration of renewable generation and coordination between production and consumption [16]. According to the European Directive on Building Performance (Directive on Building Energy Performance), all new buildings must have almost zero energy consumption after 2020. This measure is in line with the European Union's objectives in terms of fight against climate change until 2030, which also includes an improvement of at least $30 \%$ in energy efficiency as a whole. Another pioneering initiative has been developed at the La Paz University Hospital in Madrid. The project includes an important remodeling of the air conditioning system, with the construction of a thermal plant located in the hospital. This change has led to a $33 \%$ reduction in energy costs and a $50 \%$ reduction in hospital $\mathrm{CO}_{2}$ emissions.

The group has contributions for the use of piezoelectric material for the generation of walked energy or for the passing of cars on the tracks that will allow very innovative and feasible proposals, with purely Colombian engineering.

\section{Communications}

The national policy in Colombia: Digital Live Plan lfrom the ICT Ministryl introduces a preliminary analysis carried out where the successful Internet plans in the world are composed by the following five dimensions:

- Visión País, program which promotes the deployment of broadband (fiber) incorporating the structure of the industry and the positions of the interested parties.

- Regulation, that is, the obligation to separate the central network and the last mile or the establishment of price limits to access the network.

- Initiatives to increase demand, which include legislative measures and plans to increase the demand for ICT: for example, the offer of Internet and computers in schools, e-government, electronic health and e-learning.

- Infrastructure construction process (for example, fiber) which includes the set of needed actions to complete the deployment of the network, where it is necessary to involve the interested parties (business partners, shareholders and suppliers).

- The smart communications of the city are defined in several scenarios: communications between people, communications between the government and people, communications people - machines and machine - machine communications.

The communications between people are framed in the channels created for the exchange of ideas between them. The communications between the government and people are the channels created so that people have access to the services offered by the government. The communications people - machines are the channels created to access the digital services from the environment and the necessary metadata for a correct change. To end, machine-machine communications refer to the technologies and ontologies necessary for the efficient exchange of data and information between devices.

The group already has emergency communications projects between citizens and police using cell phones which show the routes that the officers must follow for an immediate response.

\section{Smart portable devices}

Smart wearable devices become an assistant in various tasks. For example, about health, a patient can use them to evaluate their health status or exercise regimen without professional help. Similarly, these devices can help to control blood glucose level, body temperature, heartbeat, cardiovascular problems, vision quality and 
chronic ailments. These devices have been a boom for diabetic, asthmatic and cardiac patients. Products such as exercise tracker or exercise bands have gained great popularity among fitness enthusiasts. Companies like Fitbit and Under Armour are showing new technologies in these products that are being involved in multiple activities that can be controlled remotely and help people. In this aspect, innovation is fundamental and the inclusion of technologies such as Blockchain for information systems that require applications.

Smart pulse oximeter: it helps to control the heart rate, the arterial oxygen saturation $\left(\mathrm{SO}_{2}\right)$, the respiratory rate and the perfusion index of the person. The device checks the amount of oxygen and hemoglobin in the blood. They are practical products and anyone can handle them by placing them on the tip of the finger or on the lobe of the ear. They are beneficial in critical emergency care, patients with respiratory problems or self-diagnosis and sleep disorders. Professionals such as pilots, mountaineers and athletes who need to control the level of oxygen at high altitude or monitor physical activity can use this product effectively.

This category includes smart watches to make calls and send text messages that can help people to follow their physical activities. They already come with long-lasting batteries and can control life activities such as calories burned, active minutes, sleep patterns, heartbeats, tracking of distances traveled and so on. Almost all major smartphone companies are developing these watches to take advantage of its growing market.

3D printed pills: the US Food and Drug Administration approved these pills for the first time in 2015 . The first medication was called Spritam and it is used for seizures in children and adults with epilepsy. They are porous pills that dissolve with a sip of water just like any other pill. With 3D pills, medications can be customized according to the medical treatments.

Smart contact lenses: they are developed by Google and help people with vision problems and diabetes. They measure the glucose level of tears in the person's eye and help to restore the eye's natural autofocus.

Smart Bras: they are useful to identify the state of mammary health in women. They are integrated with sensors that control breast tissues and alert against any cancer symptom. They are connected to an application that registers information and guides users about the proper care of breast health. They are also useful in monitoring physical activities, respiratory counting and heart rate.
We could continue listing more devices but the goal is to keep these ideas active for the projects that will be proposed in the group's universities and others which could join it.

\section{Security}

There are two important areas that are addressed in security in smart cities: 1 . Security for the person and the machines and 2. Information security. The first one deals with the integrity of both the individual and the machine or device that provides a service to the individual, this includes the systems that make up the security services (Police, Prosecutor's Office, CTI, etc.) and private security. Secondly, it is about cyber security and what is known as forensic computing or in this case where we will even have connected devices, it is called digital forensic analysis.

In terms of security dimension, working with the National Police for the development of a technological platform reduces and counteracts the level of insecurity in the neighborhood.

\section{Emergency and warning systems}

Emergency systems or alerts refer to the use of communication channels to effectively deliver messages to citizens in real time. They also refer to the use of systems based on hardware and software to monitor relevant physical variables in the prediction of emergencies or catastrophes for which it is relevant to have a prior reaction.

\section{Simulation of virtual environments}

The simulations of 3D virtual environments allows user interaction through avatars and the incorporation of learning management systems, control of variables within a specific space, planning and monitoring decisions within a city.

OpenSimulator is a BSD free code simulator for 3D virtual environments; in Figure 2, it is shown the creation of avatars for each person within the environment with unique information (password, name), each avatar will be the representation of each person in the virtual world, which has access to a private chat laddressed to another avatar) or a global chat (where everyone has access to this message), it can also be moved anywhere in the virtual world.

Some emblematic buildings of Bogotá have been designed and implemented, such as Monserrate, Maloka, Ramón Eduardo D'Lyz Nieto Library and some faculties of the Francisco José de Caldas District University. 


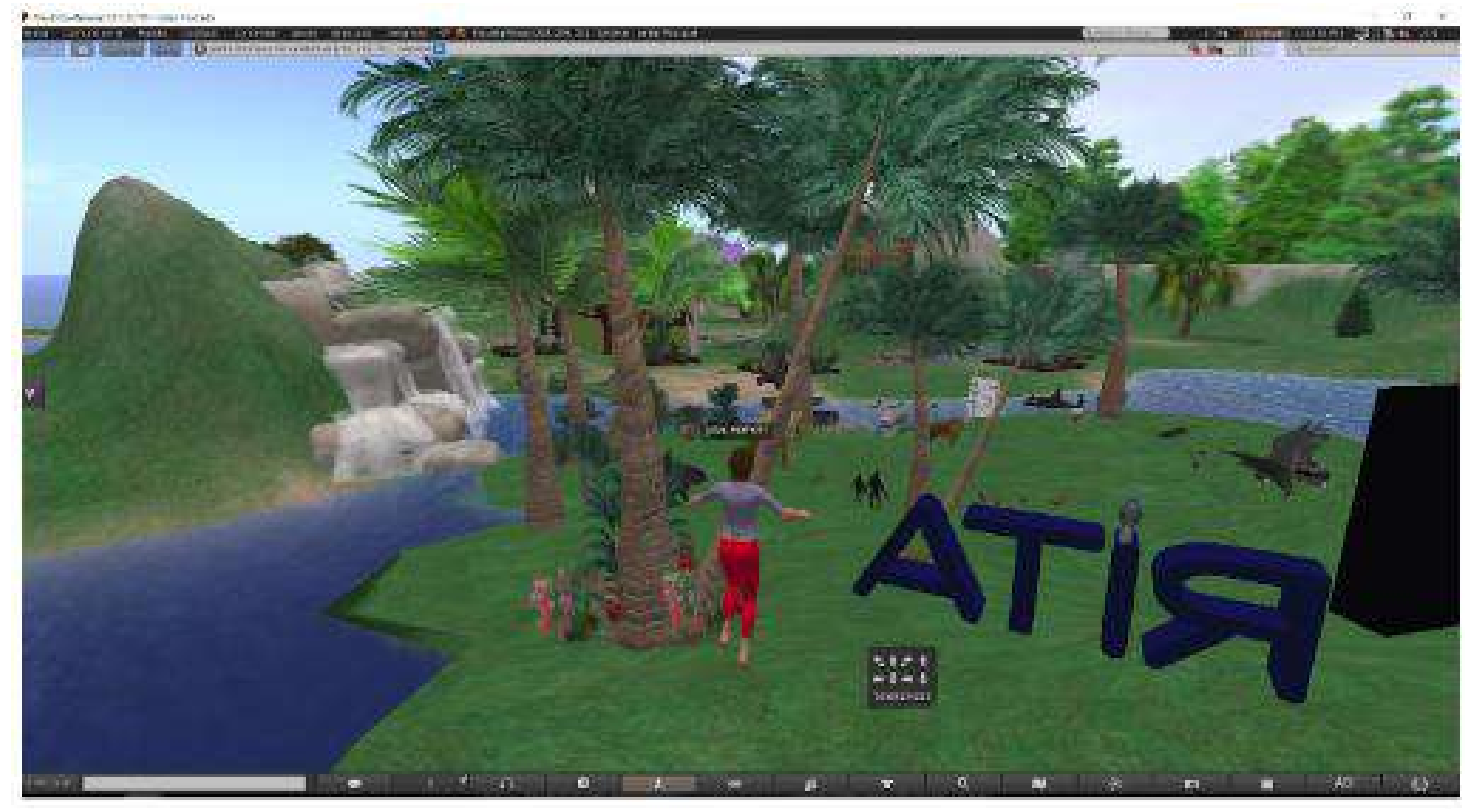

Figure 2 Virtual 3D environment with OpenSimulator

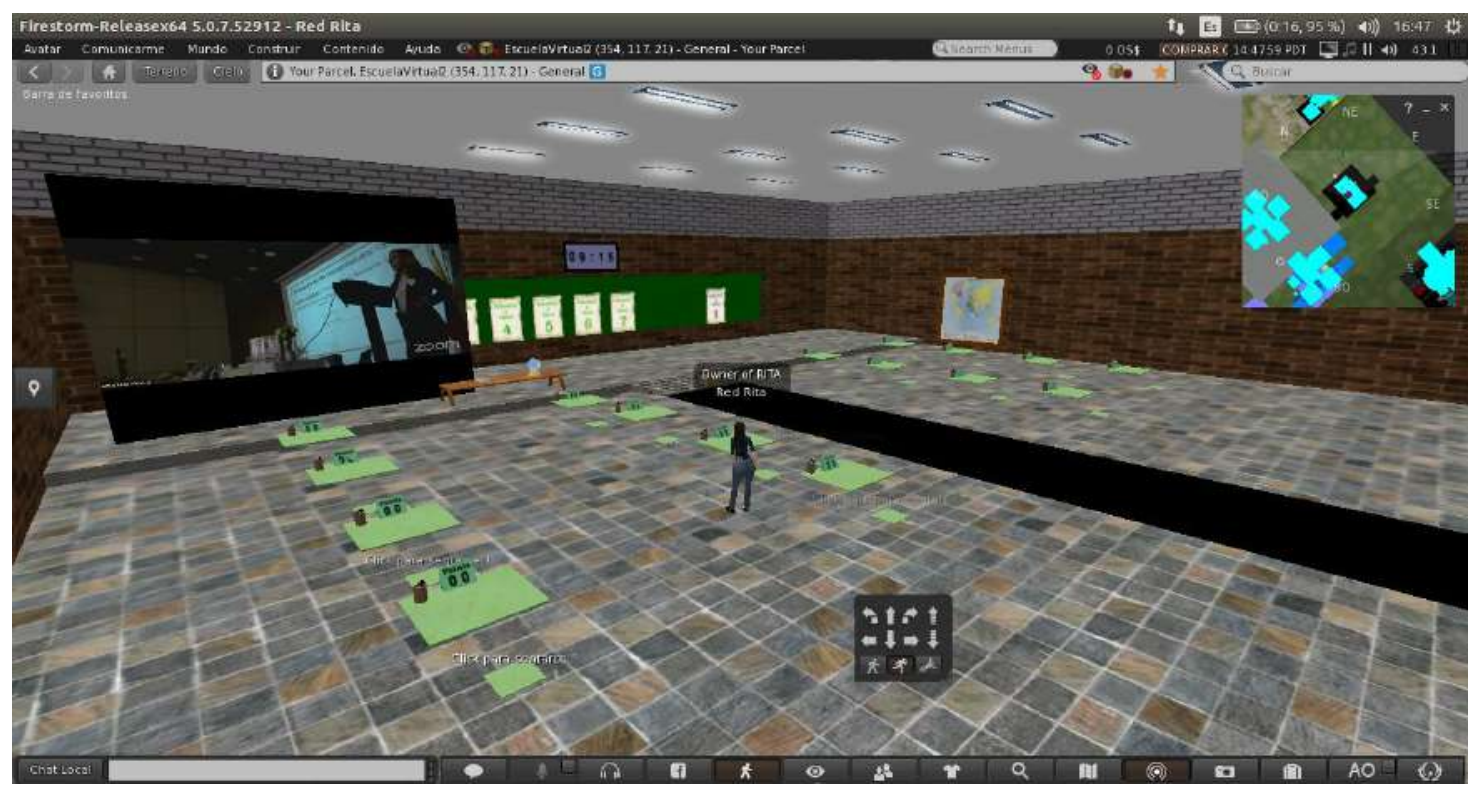

Figure 3 Virtual class simulation with OpenSimulator and LSL

LSL (Linden Scripting Language) is a language in which the OpenSimulator scripts are developed. In Figure 3, it is shown how these scripts allow a greater interaction between avatars and virtual world to improve the experience and have access to services such as a videoconference in a given topic, which simulates a totally virtual class. The avatars are directed to a specific site within the virtual world where the teacher is virtual and they take the class.

This technology has been received by some of the group's universities and will contribute to the purposes of the Smart City.

\section{Noise assessment}

As part of the Smart City project development, the noise assessment around the universities that participate started. The study involves two main approaches at Jorge Tadeo Lozano University. The first one consists in measure the noise by means of sound level meters located in spots following a grid established according to Colombian ambient noise statute (Resolution 627, 2006). In the second one, a noise simulation was done considering 
information such as buildings, streets obtained during measurement campaigns. A distance less than 250 meter, between points, was chosen to do the measurements. The mesh goal was to cover noise hot spots in the study area, which generally coincide with streets intersections or agglomeration for this case. In Figure 4, the grid used to do the measurements can be seen. Here, spots 4 and 6 correspond to Jorge Tadeo University entrance and main square, respectively. The other ones registered the noise behavior in some principal streets that surround the university. Measurements were taken 1.5 meters from the floor and away from others surfaces in order to avoid near reflections using a sound level meter type 1. In Figure 5, spots 6 and 2 are showed. Noise results. Results were evaluated according to Colombian ambient noise statute [17]. In the statute, it is necessary to establish if noise levels measured complies with vales assigned to each sector type, which is determined based on the Territorial Arrangement Planning of every municipality in Colombia (POT). In Table 1 noise results can be seen. As can be

Table 1 Noise results at measurement spots

\begin{tabular}{lllll}
\hline Spot & $\begin{array}{l}\text { LeqA } \\
\text { (Measured) }\end{array}$ & $\begin{array}{l}\text { LeqA } \\
\text { (Simulated) }\end{array}$ & $\begin{array}{l}\text { Difference } \\
\text { (dBA) }\end{array}$ & $\begin{array}{l}\text { Compliance } \\
\text { with POT }\end{array}$ \\
\hline 1 & 70.7 & 72.4 & 1.7 & No \\
2 & 70.4 & 67.8 & 2.6 & No \\
3 & 69.3 & 71.0 & 1.7 & No \\
4 & 63.8 & 67.2 & 3.4 & No \\
5 & 67.2 & 70.4 & 3.2 & No \\
6 & 61.2 & 68.1 & 6.9 & No \\
7 & 73.5 & 71.8 & 1.7 & No \\
8 & 70.7 & 69.9 & 0.8 & No \\
\hline
\end{tabular}

seen in Table 1, differences between measurements and simulation are maximum $2.6 \mathrm{~dB}$ in spots were traffic noise is the main noise source, which means that the noise prediction method used for the simulation, in this case NMBP Routes 96, get to model the behavior of noise in the area of study. On the other hand, spots 4, 5 and 6 present the major differences when compared with simulation. This can be explained because of the noise source in those spots are voices. Additionally, results show that noise levels measured does not comply with vales established by the statute 627 (65 dBA) for sector B. Consequently, it is necessary to implement actions plants in favor of reducing noise levels. As actions plans can be considered traffic management strategic which considered reduce the number of heavy vehicles than transit on the streets. In Figures 6 and 7, noise maps generated in 2D and 2.5D can be seen.

Additionally, until the publication of this document, environmental noise studies are being carried out in four other universities. These studies will make it possible to obtain noise indicators to assess the quality of life of citizens who live in or transit through these areas applying smart cities concepts [18].
The scope of this research highlights the possibility of including the use of environmental monitoring systems, which include sound pressure meters. This will allow the development of dynamic noise maps that allow the taking of actions in real time where areas of conflict are identified and actions are taken by the competent environmental entity [19].

Similarly, the use of Information and Communication Technologies (ICT) also opens a large number of possibilities by identifying significant noise sources in an environment and applying control over them, an experience successfully implemented in Singapore [20].

Drain gratings. An $\mathrm{R} \& \mathrm{D}+\mathrm{i}$ project is started to avoid rainwater floods in the boundaries of the universities in Bogotá [21], through the control, status and management of drain gratings located at said boundaries. The objective of the project is the design and construction of a Geotechnical Management simulator (SGG) for the proper use of these grids called SIGMAR that allows, through the mining of public geodata, algorithms and models monitored under the early warning approach on strange masses and precipitation of the flow of rainwater that alter the proper functioning of this type of sewage system.

In 2018, the first phase of the project began at the Minuto de Dios University thanks to the Technologies and Innovation Solutions group, assigned to the Systems Engineering Faculty, under the direction of the cooperative VISIBILITY research group with the IT-UNIMINUTO research group. Figure 8 shows the map of the study area where students make their field trip with the counting, measurement and assessment of the grids surrounding the boundaries of the institution.

Then, through georeferencing software, photos were taken of the study area, highlighting more precise data such as measurements, weights and states of the grids. Also, five assessment instruments (closed survey) aimed at formal and informal commerce, educational community, academic community, social community and neighborhood government entities were built, in order to get to know the perception of the stakeholders involved in the solution of the situation current situation that occurs with floods at the boundaries of the University.

In phase II, it is expected that the project has allowed to apply these instruments and show the highlights of the correlation of the data obtained in the field output and in the georeferential application in the study area. In order to continue advancing the project and disseminating the results obtained so far. It took some georeferential photos of the Engativá locality, its stations, climate control, and 


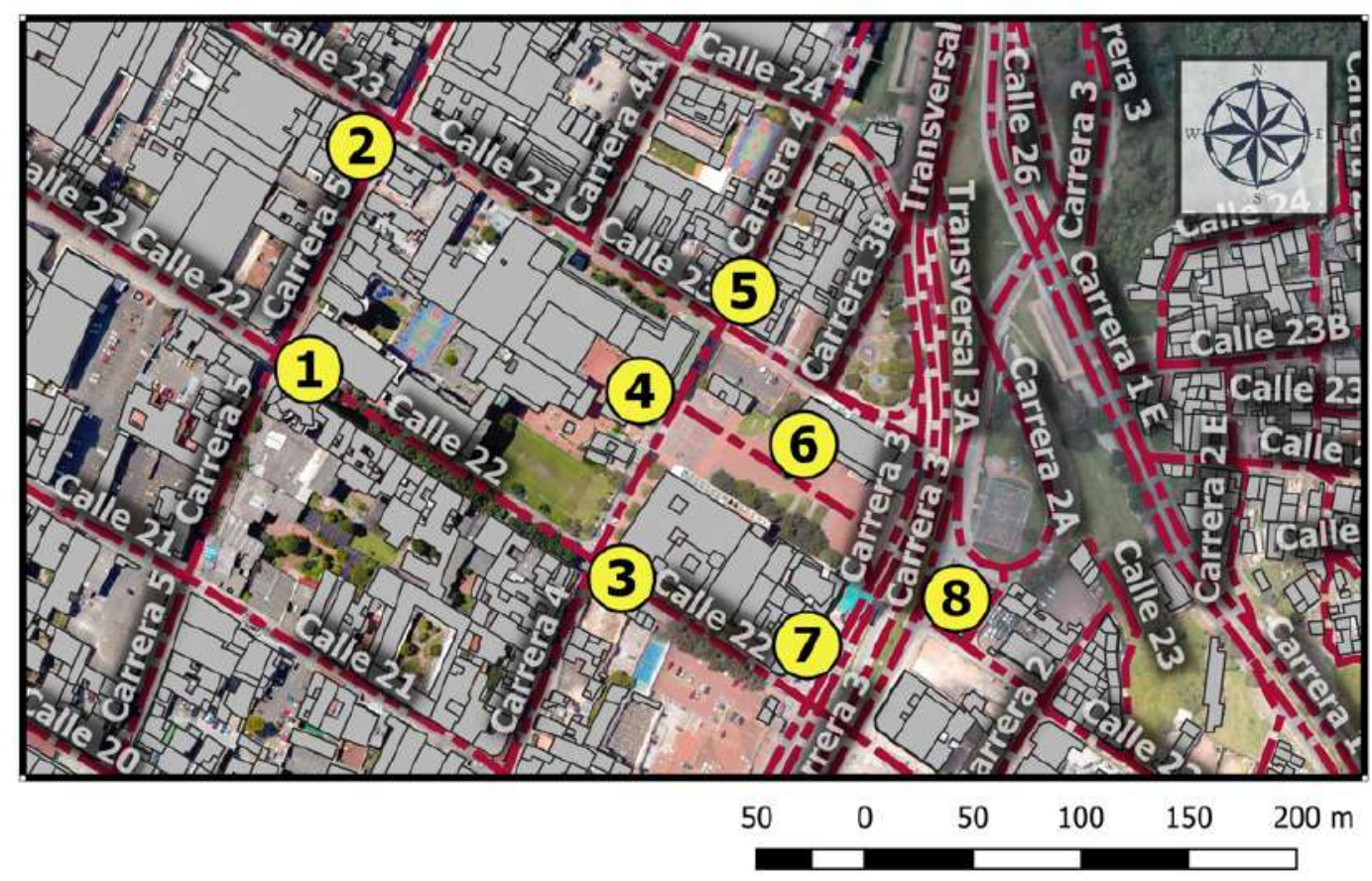

Figure 4 Area of study with noise measurement spots

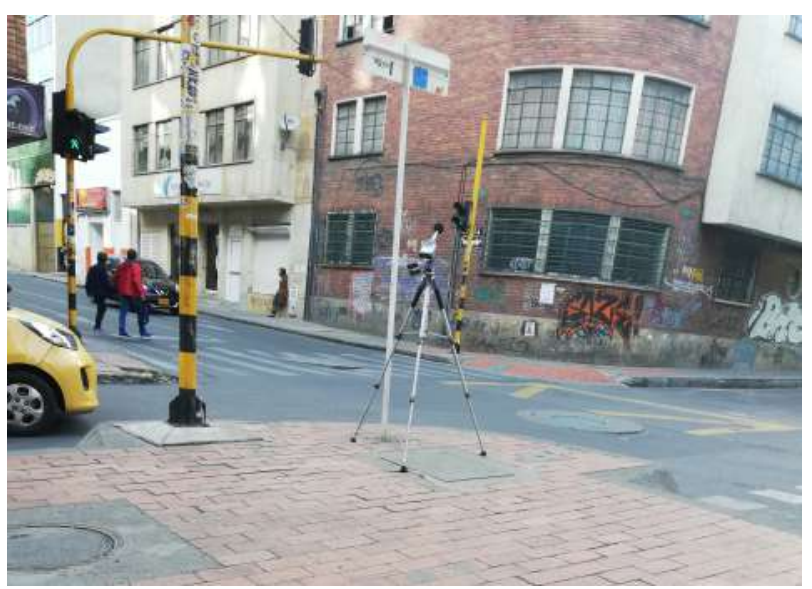

Figure 5 Measurements in spots 2 (left) and 6 (right)

soil study, above all.

Smart Parking Cycle. The use of bicycles in Bogota is increasing. "Bogotá has the largest cycle-route network in Latin America, with more than 340 kilometers of exclusive lanes, which cover the entire length of the city." [22], due to mobilization problems (comfort, travel time, security, etc.), to citizen awareness and compassion for the environment, and many people are aware of the damage that is being caused to the planet with high pollution rates.

Seeing the bicycle as a great aid option for sustainable development and taking into account the boom that smart cities have taken, some people have been establishing smart parking cycles that are based on the storage of bicycles supported by electronic devices for the recognition of people and to avoid the theft of bicycles. Figure 9 shows some biometric fingerprint equipments, the use of keyboards for identification by private keys, radio frequency identification (RFID) technologies based on the use of labels (cards used by each person to identify) and readers (located in each parking lot cycle to verify that the label is valid).

The main objective is to use the technologies (NFC, Databases, servers) to solve a problem in the parking cycle (theft, identification, storage, organization, etc.), implementing a system of bicycles parking, creating a method of entry and storage in a smart parking where, through requests sent to a server Node, available spaces are obtained so that a bicycle can be stored. Figure 10 shows the communication between the client and the parking lot cycle by NFC technology, using NFC tags where each tag brings an UID and all the user-based information. A Raspberry is in charge of the control of mechanical movement (Motors, drivers, sensors, etc.). The communication between Raspberry and the server is mediated by http requests to create, complete and verify the registration of each user and each storage.

\section{Tracking platforms for variables of interest}

To propose an effective path of transition from a city to a Smart City, it is necessary to create valid indicators that, through actions and projects, direct efforts in a 


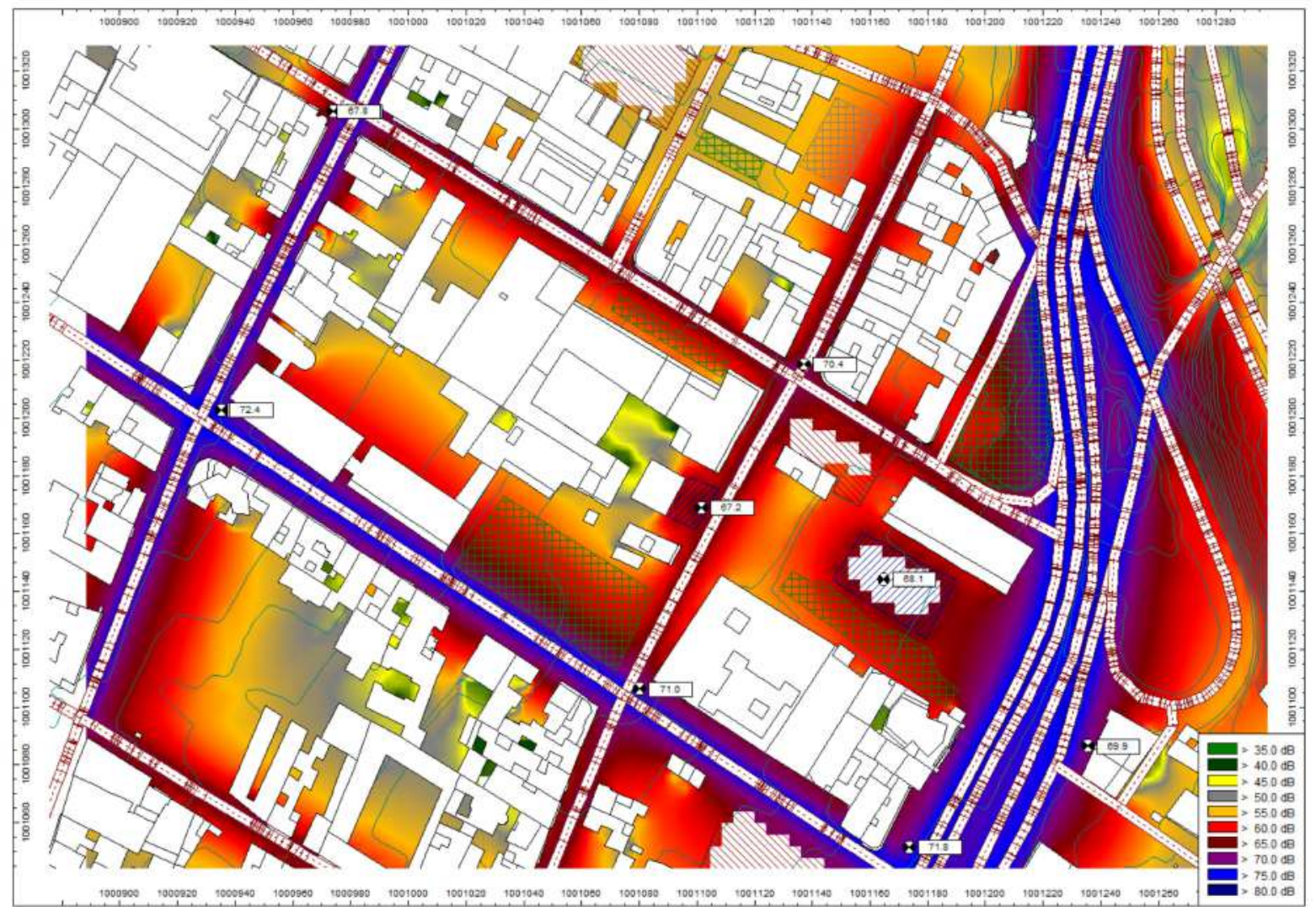

Figure 6 2D noise map in study area

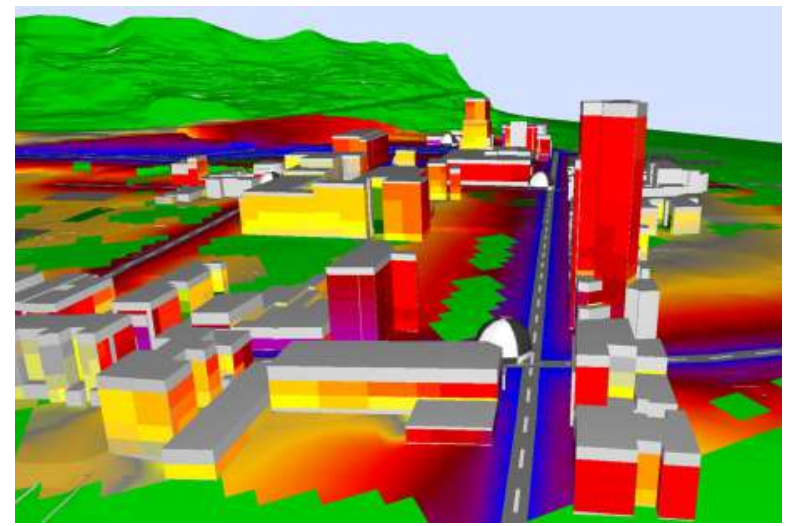

Figure $72.5 \mathrm{D}$ noise map in study area

levels as follows: the data collection by means of sensors or applications, the level of communications that moves the data for processing and the analytical stage which takes the data and converts it into information. The platforms reviewed are Lumada IoT, IoT Cloud Einstein, Watson IoT, Telit, Azure, Xively, Ayla, Oracle IoT, Fusion Connect, Predix, AWS IoT, WSO2, KaaloT, Thingsboard, Macchina.io, Zetta, Thinger.io.

Among all the platforms checked, Thinger.io was chosen due to its integration of agnostic hardware (It is open source and supports several devices); it has a version of Docker and AWS deployment, and has an intuitive integrated dashboard and support for analysis.

\section{Conclusions}

specific direction since to achieve them, it is necessary to measure and monitor them continuously. With a view to this objective, the analytics and data tracking platforms of the Internet of Things become the best way to carry out this monitoring, since they allow obtaining data in real time, manipulating them, generating knowledge and making decisions based on that new knowledge, helping the development of smart cities.

The IoT (Internet of Things) platforms have three functional

The creation of an initial project after 12 months of work between different areas of knowledge, with the support of RUMBO network, evidences the inter-institutional needs and competences that enhanced the interdisciplinary work.

Higher education establishes not only a constant training process but also a strategic social function 


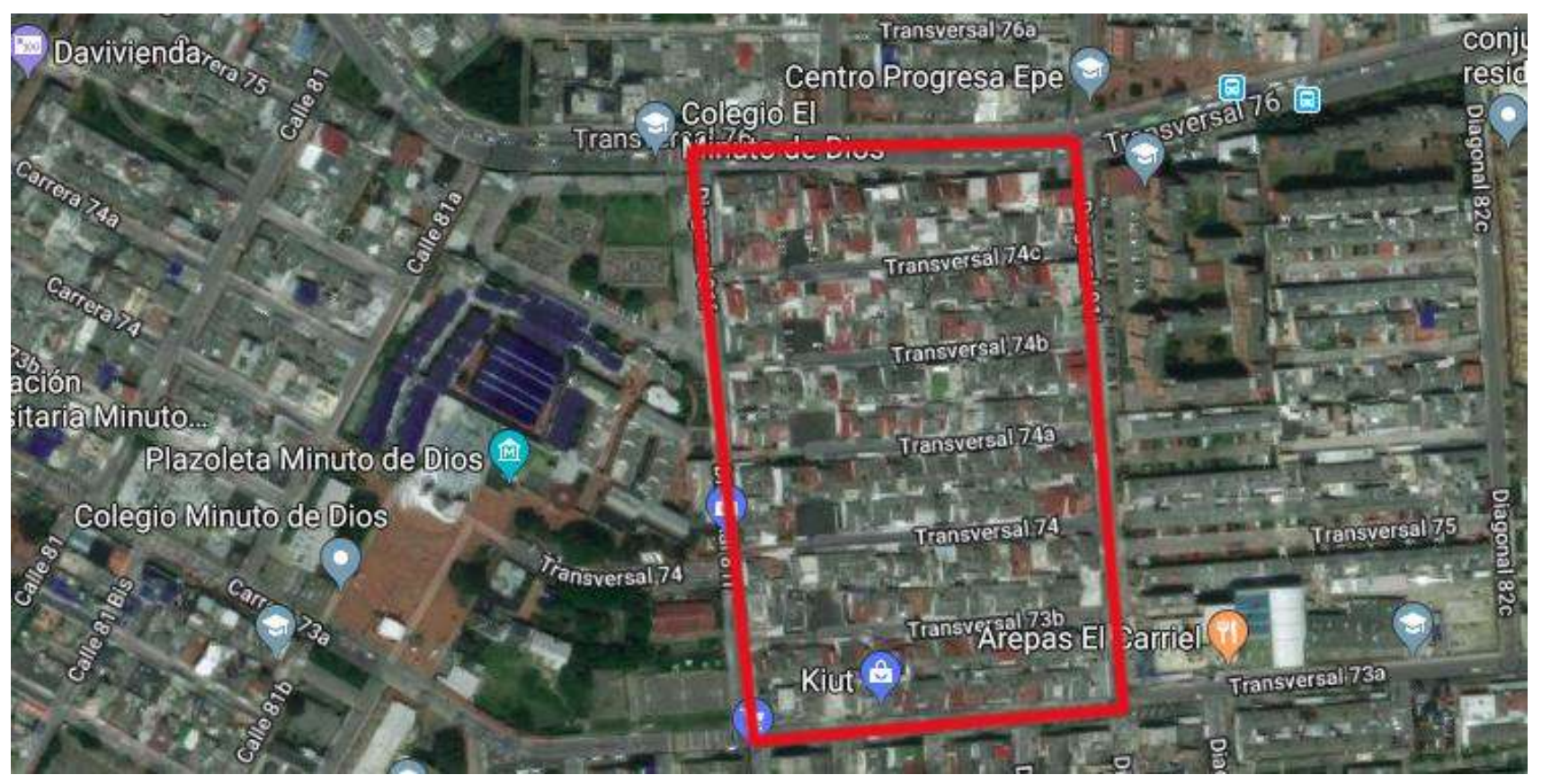

Figure 8 Map of the study area - UNIMINUTO
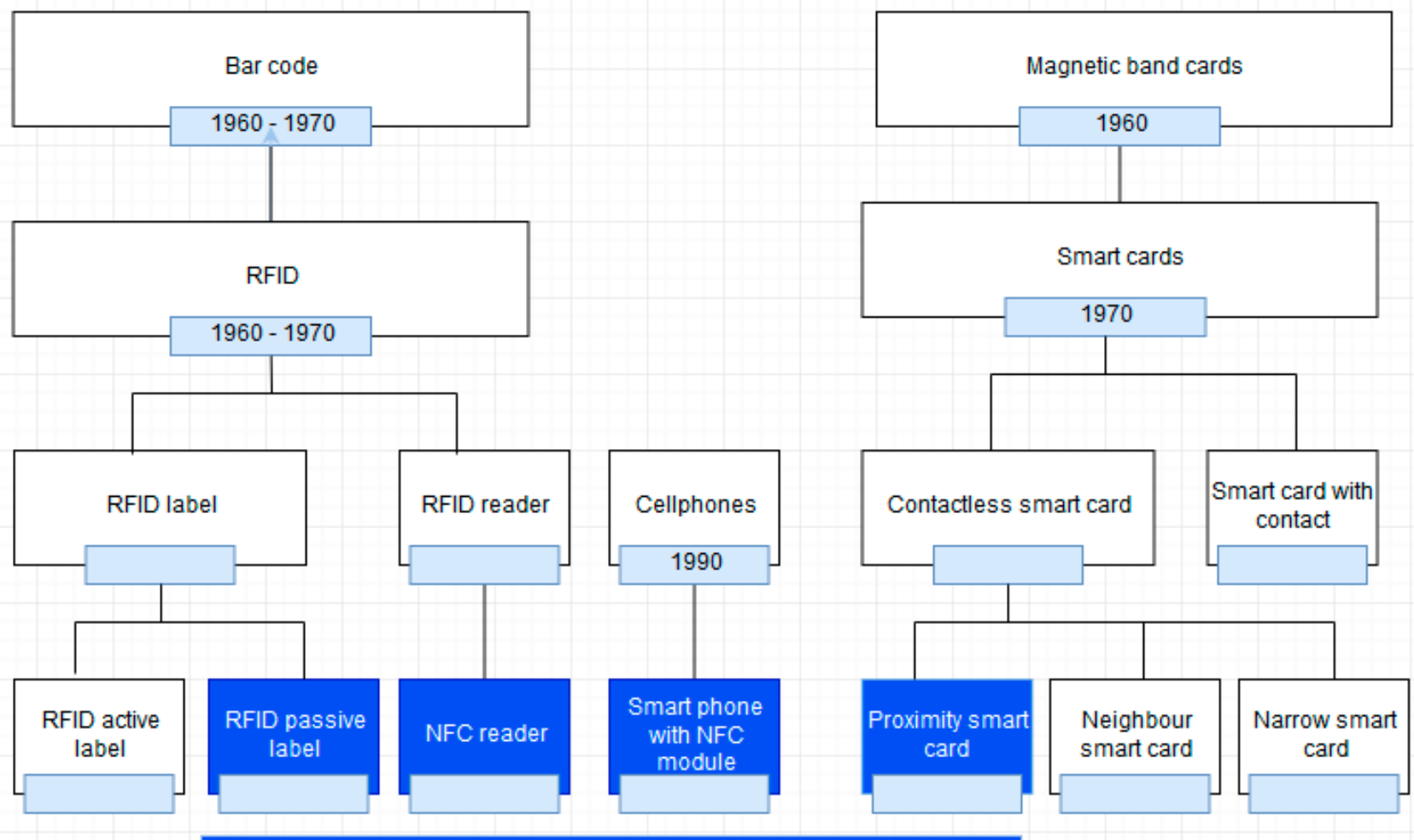

Near Field Communication - NFC

2002

Figure 9 Development and evolution towards NFC Technology (Vedat Coskun, 2013) 


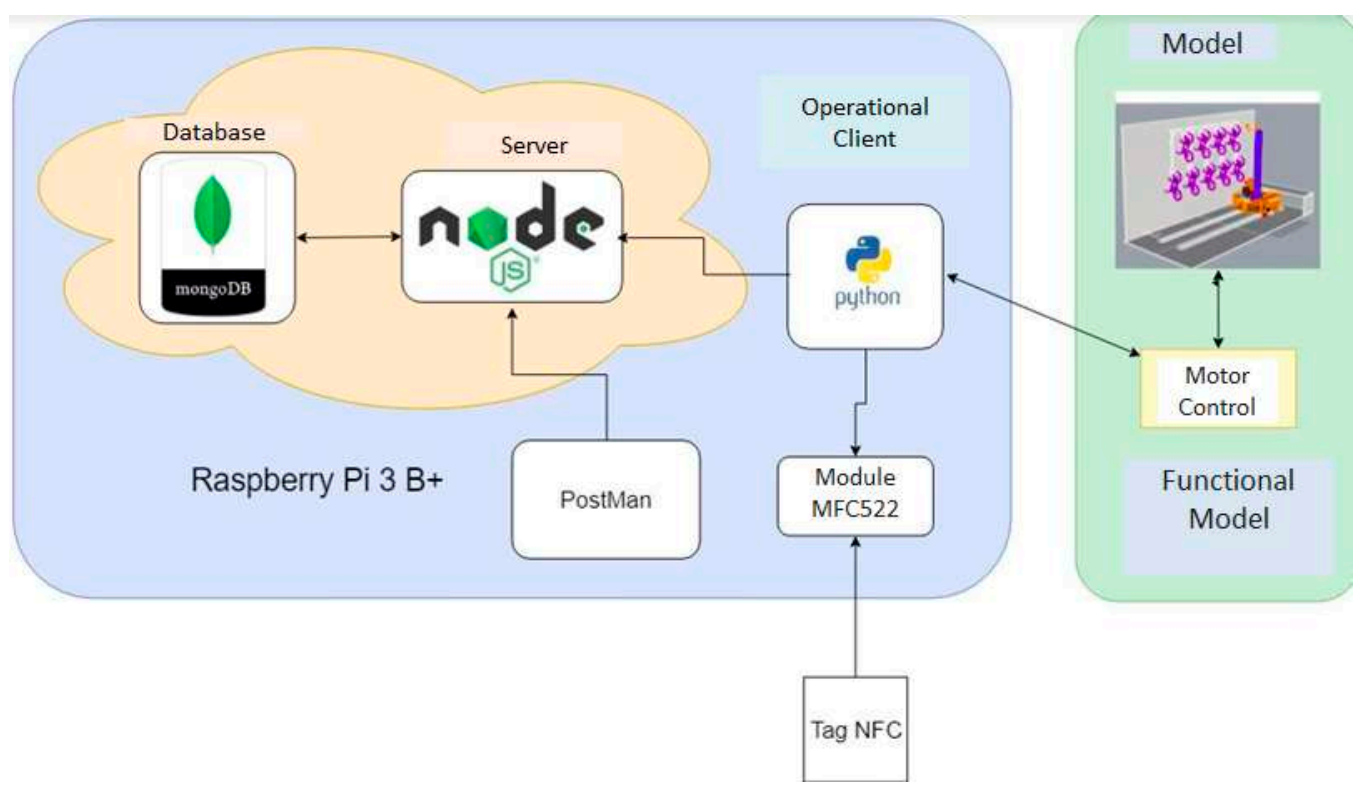

Figure 10 Development and evolution towards NFC Technology (Vedat Coskun, 2013)

that must follow the needs of the community through the pursuit of benefits and integration with Information and Communication Technologies (ICT).

The group is expected to become a relevant component in the development and transformation of the environment, allowing society to be empowered in the interactive activities and to understand its context, through access to augmented reality.

The results of this project allowed to approach the business sector, being able to reach the municipalities of Colombia and soon, sharing the results of this research work to private companies interested in this area.

In the short term, it is expected to implement more services that allow the digital neighborhood to interact with real life.

\section{References}

[1] (2014) Smart city framework - guide customer service to establishing strategies for smart cities and communities. The British Standards Institution. Accessed Feb. 05, 2013. [Online]. Available: https://bit.ly/1fH2zj4

[2] (2014) Bases del plan nacional de desarrollo 2014-2018. Departamento Nacional de Planeación. Accessed Mar. 04, 2013. [Online]. Available: https://bit.ly/1ttlCA5

[3] Consejo Nacional de Política Económica y Social. (2016, Dec. 26) Documento CONPES. [Online]. Available: https://bit.ly/13gbViS

[4] G. Crespi, A. Maffioli, and M. Meléndez, "Public support to public support to colombian COLCIENCIAS' experience," Inter-American Development Bank, Washington, EEUU, Tech. Rep. IDB-TN-264, Apr. 2011.

[5] C. Colldahl, S. Frey, and J. E. Kelemen, "Smart cities: Strategic sustainable development for an urban world," M.S. thesis, School of
Engineering Blekinge Institute of Technology, Karlskrona, Sweden, 2013.

[6] J. Mortensen, F. J. Rohde, K. R. Kristiansen, M. Kanstrup-Clausen, and M. Lubanski, Danish Smart Cities: Sustainable Living in an Urban World. Copenhagen, Denmark: Copenhagen Cleantech Cluster, 2012.

[7] 0. Salcedo, L. F. Pedraza, and C. A. Hernandez, "Intelligent semaphore model for the city of bogotá," Engineering, vol. 11, no. 2, pp. 61-69, 2006.

[8] R. G. Hollands, "Will the real smart city please stand up? intelligent, progressive or entrepreneurial?" City, vol. 12, no. 3, pp. 303-320, Dec 2008.

[9] M. T. Andersen and S. Bhandari, "Assessment and normative guidance of the collective mindset maturity regarding open data in smart cities," M.S. thesis, Aalborg University, Copenhagen, Denmark, 2015.

[10] R. P. Dameri and C. Rosenthal, Smart City How to Create Public and Economic Value with High Technology in Urban Space, 1st ed. Springer International Publishing, 2014.

[11] T. Nam and T. A. Pardo, "Conceptualizing smart city with dimensions of technology, people, and institutions," in $12^{\text {th }}$ Annual International Conference on Digital Government Research, New York, EE.UU, 2011, pp. 282-291.

[12] D. Toppeta, "The smart city vision: How innovation and ict can build smart, "liveable", sustainable cities," Think! The Innovation Knowledge Foundation, Tech. Rep. 005/2010, Oct. 2010.

[13] R. Giffinger and et al., "Smart cities - ranking of european medium-sized cities," Centre of Regional Science, Vienna UT, Vienna, Austria, Tech. Rep., Oct. 2007.

[14] D. Satterthwaite, "Cities' contribution to global warming: Notes on the allocation of greenhouse gas emissions," Environment and Urbanization, vol. 20, no. 2, pp. 539-550, Oct 2008.

[15] M. Hernández, S. Ortiz, and C. E. Vasco, "Informe de la mision de sabios, colombia: al filo de la oportunidad," Consejeria presidencial para el desarrollo institucional, Presidencia de la Republica, Bogotá, Colombia, Tech. Rep., 1996.

[16] I. García, G. Palacios, R. Lacuesta, and J. Lloret, "ABSCEV: An agent-based simulation framework about smart transportation for reducing waiting times in charging electric vehicles," Computer Networks, vol. 138, pp. 119-135, Jun 2018.

[17] Ministerio De Ambiente, Vivienda y Desarrollo Territorial. (2006, Apr. 07) Resolución 0627. [Online]. Available: https://bit.ly/2F9nrCY 
Nancy E. Ochoa Guevara et al., Revista Facultad de Ingeniería, Universidad de Antioquia, No. 93, pp. 41-56, 2019

[18] C. Asensio, "Acoustics in smart cities," Appl. Acoust., vol. 117, no. Part B, pp. 191-262, Feb 2017.

[19] P. Bellucci, L. Peruzzi, and G. Zambon, "LIFE DYNAMAP project: The case study of rome," Appl. Acoust., vol. 117, no. Part B, pp. 193-206, Feb 2017.

[20] A. Agha, R. Ranjan, and W. S. Gan, “Noisy vehicle surveillance camera: A system to deter noisy vehicle in smart city," Appl. Acoust., vol. 117, no. Part B, pp. 236-245, Feb 2017.
[21] Normas de la Empresa de Acueductos y alcantarillado de Bogotá (E.A.A.B), NORMA NS-047 Versión 4,1 (Sumideros), Empresa de Acueducto y Alcantarillados de Bogotá, Bogotá, Colombia, 2007.

[22] (2009) Movilidad en bicicleta en bogotá. Camara de comercio de Bogotá. Accessed Aug. 01, 2015. [Online]. Available: https: //bit.ly/2f4ij2y 